Lind and Jasra. HCA Healthcare Journal of Medicine (2021) 2:3

https://doi.org/10.36518/2689-0216.1329

\title{
Editorial
}

\section{Competency-Based Medical Education and Breast Disease}

David Scott Lind, MD, FACS,' Bharti Jasra, MBBS, FACS²

\section{Abstract}

\section{Description}

The future delivery of high quality, patient-centered breast care is fundamentally dependent on how we train the next generation of breast care providers. As medical educators, we have a tremendous opportunity to transform how clinical skills related to breast care are taught and assessed and thereby, improve breast patient outcomes. This article reviews the current state of education and ideas for implementing a learner-specific, competency-based curriculum to teach breast care skills.

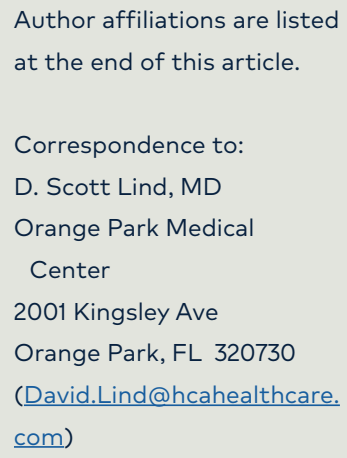

Author affiliations are listed

Correspondence to:

D. Scott Lind, MD

2001 Kingsley Ave

Orange Park, FL 320730

$\underline{\mathrm{com}}$

\section{Keywords}

breast cancer; breast disease; medical education; educational measurement; medical students; clinical competence

Given the enormity of breast cancer as a health issue, it is essential that all healthcare providers demonstrate a minimum level of clinical competency related to breast care. Unfortunately, however, the current state of breast education in the health professions needs attention. Anecdotal observations plus the medical literature demonstrate critical deficiencies in the core clinical skills related to breast care across the continuum of medical education. These basic deficiencies will ultimately impact the outcomes of patients with a breast complaint. This article briefly reviews the current state of education related to breast care in the health professions. Although this syllabus presents primarily a surgical perspective, these observations are equally applicable to nonsurgical disciplines. While significant system-wide changes are slowly being implemented, ${ }^{2}$ there remains an urgent need for a learner-specific, competency-based curriculum to teach and assess breast care skills across the continuum of medical education.

On many clinical rotations, medical students have become marginalized, passive observers with brief, random exposures to patients with breast complaints. ${ }^{3}$ Students largely learn isolated facts related to breast diseases that are dissociated from patient care. In addition, faculty face ever increasing clinical productivity pressures that severely limit their time to teach and, as a result, many faculty have relinquished student teaching and even end-of-rotation student assessments to residents. Remarkably, most medical students graduate without having been directly observed performing a focused history and breast exam. ${ }^{4}$ Therefore, students receive little formative feedback related to breast-specific competencies. Finally, rotation summative assessment consists primarily of subjective, recall-biased evaluations and the National Board of Medical Examiners (NBME) subject exam, neither of which specifically address breast-related clinical skills. Consequently, when surveyed, graduating students report a lack of confidence and preparedness for residency regarding many essential clinical skills. ${ }^{5}$

Simulation has been incorporated into most health professions curricula. Simulation can standardize clinical content and provide a safe learning environment with the opportunity for

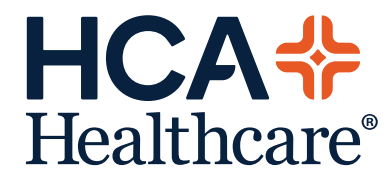

www.hcahealthcarejournal.com

(c) 2021 HCA Physician Services, Inc. d/b/a Emerald Medical Education

\author{
HCA Healthcare \\ Journal of Medicine
}


repetitive practice without consequence to a real patient. Kotranza et al. developed and validated a mixed reality human (MRH) breast simulator (interactive virtual patient with a breast complaint linked to a mannequin-based breast simulator) that permits students to take a breast-focused history and perform a breast exam. ${ }^{6}$ The MRH breast simulator was successfully integrated into a surgery clerkship with the requirement for students to perform a virtual breast history and exam on a virtual breast patient with feedback before interacting with a real patient with a breast complaint. Current efforts are directed towards determining the minimum acceptable core level of competency for students to achieve while interacting with the breast $\mathrm{MRH}$. Other investigators have also used breast mannequins with innovative sensor technology to teach and objectively assess clinical breast exam skills. ${ }^{7}$ Azari et al. recently reported the use of novel video motion capture and video tracking to compare the hand motions of physicians performing a clinical breast exam. The video tracking technology shows promise and may be useful for objective, evidence-based training, assessment and credentialing. ${ }^{8}$

The management of breast disease is an essential component of general surgery and comprises $15-25 \%$ of a typical general surgeon's practice. ${ }^{9}$ Unfortunately, surgery residents also demonstrate core deficits related to the management of breast disease. In fact, data suggests that some basic breast skills may even regress during residency. ${ }^{10}$ The American Board of Surgery (ABS) defines breast disease as part of the Breast, Skin and Soft Tissue core content component of general surgery residency." Several reasons account for resident inadequacies related to breast patient management. The frenetic pace of health care together with resident service demands have severely curtailed the learner time required for reflection and deliberate practice of clinical skills. Traditionally, case numbers have dictated surgery resident procedural competence. The ABS requires a minimum 25 cases over 5 years as the operating surgeon in the Breast, Skin and Soft Tissue category." Although many residents go on to pursue subspecialty fellowships, including breast fellowships that provide significant further experience in breast surgery, the majority of breast cancer operations are performed by general surgeons. ${ }^{12}$ Therefore, we must ensure graduating general surgery residents are competent to perform the essential common breast operations. Unfortunately, however, case number is not equivalent to competence. Even when residents fulfill ABS numbers requirements, resident operative logs fail to define the degree of involvement and autonomy in the case or the learning outcomes from their operative experiences.

To specifically determine exposure of general surgery residents to breast cancer operations, surgical educators at the University of Pennsylvania recently queried the American College of Surgeons (ACS) National Surgical Quality Improvement Program (NSQIP) database. ${ }^{13}$ From 2008-2011, residents were involved in 23,996 of 58,413 breast operations. When resident participation was analyzed by PGY level, junior residents (PGY1-3) were more likely than senior residents (PGY4-5) to be involved in the "essential common" breast operations such as breast biopsy, mastectomy (partial, simple and modified radical), sentinel node biopsy and axillary dissection (PGY1-3=72\% versus PGY4$5=28 \%$; $p<0.001$ ). One potential reason for the junior resident heavy participation in breast cases is that in many general surgery residency programs chief residents frequently delegate "less complex" breast operations to the more junior residents on the service. The authors also examined the Accrediting Committee for Graduate Medical Education (ACGME) database for the same academic time period and found that breast operations comprised approximately $7-8 \%$ of the junior residents' operative experience while comprising only 3-4\% of chief residents' cases. If recent ABS recertification data shows that breast operations comprise from $15-25 \%$ of a general surgeon's annual case volume, then breast cases are dramatically underrepresented in the operative experience of general surgery residents, particularly in the critical final year. Therefore, there is an immediate need to develop a valid and reliable assessment tool for the common breast procedures. The operative standards and critical steps for the common breast cancer operations (i.e., partial/ total mastectomy, sentinel node biopsy and axillary dissection) has recently been published by the American College of Surgeons (ACS) in Operative Standards for Cancer Surgery Volume 1: Breast, Lung, Pancreas and Colon. ${ }^{14}$ This re- 
cent ACS publication provides the blueprint for resident breast procedure teaching, feedback and competency-based assessment.

Procedural simulation has been incorporated into all general surgery training programs. Box trainers and virtual reality (VR) simulators are significantly utilized by training programs for resident acquisition laparoscopic skills. The Fundamentals of Laparoscopic Surgery (FLS) is a competency-based curriculum to teach and assess residents the basics of laparoscopy. ${ }^{15}$ All residents must complete the FLS module to "sit for their general surgery boards". Unfortunately, simulated models of open surgery have lagged behind minimally invasive VR simulators. There is an urgent need to create and validate simulated models of the common breast procedures to teach and assess resident operative skills.

While competency-based assessment of breast procedures is important, perioperative decision-making skills are also critical to the successful management of breast patients. In fact, many breast cancer management decisions are made in a clinic and/or a multidisciplinary breast conference where resident attendance is frequently lacking. Since "assessment drives the curriculum", the ABS emphasis on the number of procedures required for board certification drives residents to choose the operating room over clinic and multidisciplinary breast conferences, which limits residents' ability to acquire these essential decision-making skills. To make matters worse, resident summative assessment regarding cognitive knowledge related to breast care is inadequate. Like residents in other disciplines, general surgery residents take an annual in-service training examination. The American Board of Surgery In-Training Examination (ASBITE) is a multiple choice question (MCQ) exam administered annually at the end of January to general surgery residents." Surgical educators at the University of Florida examined a decade's worth of ABSITE scores for residents in their general surgery program and not surprisingly, they found that residents who had done a breast rotation within 6 months of the ABSITE exam had fewer incorrect breast-related ABSITE questions. Furthermore, breast-related questions on the ABSITE exam represented only approximately $4 \%$ of the entire exam ${ }^{16}$ In order to reiterate, since breast patients represent $15-25 \%$ of a typical general surgeon's practice, breast-related procedural requirements and cognitive assessments are underrepresented in general surgery training programs. The ABS requires passage of the General Surgery Qualifying (MCQ exam) and Certifying Examinations (oral exam) for board certification. Although data regarding breast-specific content and resident breast-specific performance on the ABS exams is not published, anecdotal reports suggest that residents consistently underperform on the breast-related clinical scenarios.

Generally, medical education has failed to keep pace with the recent dramatic changes in health care and more specifically breast care. The management of breast cancer is a rapidly changing field that makes it difficult for even an expert to stay current, however, there are basic, level-specific breast competencies that can be defined, taught and assessed. Medical education is slowly shifting from a rigid, timebased system, focused on process measures, to an adaptable, competency-based structure with more emphasis on outcome measures. ${ }^{17}$ Competency-based education (CBE) is a framework for designing and implementing education that focuses on the desired performance characteristics of health care..$^{18} \mathrm{CBE}$ defines observable, measurable performance metrics that learners must attain to be considered competent. Two important concepts that have become important related to $\mathrm{CBE}$ are milestones and entrustable professional activities (EPAs). Milestones describe specific levels of performance that must be achieved annually for advancement..$^{19}$ EPAs are essential tasks or responsibilities of professional practice that will eventually be entrusted to the unsupervised performance by a trainee. ${ }^{20}$

How do we need to proceed to improve the current state of breast education in the health professions? First, we must define the core breast competencies (Milestones and EPAs) across the continuum of medical education and practice. Then, we must develop and implement curricula to teach and assess these competencies. Finally, we must translate the model of big data related to patient care to medical education and develop a longitudinal educational database (i.e., student > resident - fellow p practicing clinician) that is linked to 
breast patient outcomes, so we can track educational efforts related to those outcomes.

The future delivery of high quality, patient-centered breast care is fundamentally dependent on how we train the next generation of breast care providers. While medical education is regulated by an alphabet soup-like, isolated group of accrediting organizations (i.e., LCME, ACGME and CCME), the group that will have the greatest influence on the future of medical education related to breast care is WEME or WE are Medical Education. As medical educators, we have a tremendous opportunity to transform how clinical skills related to breast care are taught and assessed and thereby, improve breast patient outcomes. Just as we, as breast specialists, set the bar for multidisciplinary collaborative care related to breast cancer patients, together let's set the standard for multidisciplinary, collaborative, outcomes-based education related to our learners across the continuum of medical education. The public and our patients expect and deserve no less!

\section{Conflicts of Interest}

Dr. Lind declares compensation for licensing a simulation technology.

Dr. Jasra declares she has no conflicts of interest.

Dr. Lind is an employee of Orange Park Medical Center, a hospital affiliated with the journal's publisher.

This research was supported (in whole or in part) by HCA Healthcare and/or an HCA Healthcare affiliated entity. The views expressed in this publication represent those of the author(s) and do not necessarily represent the official views of HCA Healthcare or any of its affiliated entities.

\section{Author Affiliations}

1. Orange Park Medical Center,Orange Park, $\mathrm{FL}$

2. University of Florida, Jacksonville, FL

\section{References}

1. Corbett EC, Whitcomb M. The AAMC Project on the Clinical Education of Medical Students Clinical Skills Education. Association of American Medical Colleges; 2004.
2. Nasca TJ, Philibert I, Brigham T, Flynn TC. The next GME accreditation system--rationale and benefits. N Engl J Med. 2012;366(11):1051-1056. https://www.nejm.org/doi/full/10.1056/NEJMsr1200117

3. Cooke M, Irby D, O’Brien B. Educating Physicians: A Call for Reform of Medical School and Residency. 1st ed. Jossey-Bass: A Wiley Brand; 2010.

4. Powell HS, Bridge J, Eskesen S, Estrada F, Laya M. Medical students' self-reported experiences performing pelvic, breast, and male genital examinations and the influence of student gender and physician supervision. Acad Med. 2006;81(3):286 289. https://journals.Iww.com/ academicmedicine/Fulltext/2006/03000/Did You Know .22.aspx

5. Graduation Questionnaire (GQ). Association of American Medical Colleges. 2021. https://www. aamc.org/data-reports/students-residents/report/graduation-questionnaire-gq

6. Kotranza A, Lind DS, Lok B. Real-time evaluation and visualization of learner performance in a mixed-reality environment for clinical breast examination. IEEE Trans Vis Comput Graph. 2012;18(7):1101-1114. https://ieeexplore.ieee.org/ document/5963665

7. Laufer S, Cohen ER, Kwan C, et al. Sensor technology in assessments of clinical skill. N Engl J Med. 2015;372(8):784-786. https://www.nejm. org/doi/10.1056/NEJMc1414210

8. Azari D, Pugh C, Laufer S, et al. Evaluation of hands-on clinical exam performance using marker-less video tracking. Proc Hum Factors Ergon Soc Annu Meet. 2014;58(1):793-797. https://doi. org/10.1177/1541931214581145

9. Pass HA, Klimberg SV, Copeland EM 3rd. Are "breast-focused" surgeons more competent?. Ann Surg Oncol. 2008;15(4):953-955. https://doi. org/10.1245/s10434-008-9835-z

10. Chalabian J, Garman K, Wallace P, Dunnington $G$. Clinical breast evaluation skills of house officers and students. Am Surg. 1996;62(10):840845.

11. The American Board of Surgery. The Booklet of Information - Surgery. The American Board of Surgery 2020.

12. Sclafani LM, Bleznak A, Kelly T, El-Tamer MB. Training a new generation of breast surgeons: are we succeeding?. Ann Surg Oncol. 2012;19(6):1856-1861. https://doi.org/10.1245/ s10434-011-2164-7

13. Conway RG, Bartlett EK, Hoffman RL, Czerniecki BJ, Karakousis GC, Kelz RR. Residents' experience in breast cancer care. J Surg Educ. 2015;72(6):1233-1239. https://doi.org/10.1016/i. jsurg.2015.04.028

14. Nelson HD, Hunt KK; American College of Surgeons Clinical Research Program; Alliance for Clinical Trials in Oncology. Operative Standards for Cancer Surgery: Volume I: Breast, Lung, Pancreas, Colon. 1st ed. LWW; 2015. 
15. Fundamentals of Laparoscopic Surgery. Society of American Gastrointestinal and Endoscopic Surgeons. https://www.flsprogram.org/

16. Lind DS, Abdalla EK, Flynn TC, Tepas JJ, Copeland EM. Breast disease-related educational outcomes at the University of Florida. Breast J. 2000;6(3):157-160. https://doi.org/10.1046/j.15244741.2000.99035.x

17. Nasca TJ, Weiss KB, Bagian JP, Brigham TP. The accreditation system after the "next accreditation system”. Acad Med. 2014;89(1):27-29. https:// journals.Iww.com/academicmedicine/Fulltext/2014/01000/The Accreditation System After the Next.13.aspx

18. Gruppen LD, Mangrulkar RS, Kolars JC. The promise of competency-based education in the health professions for improving global health. Hum Resour Health. 2012;10:43. https://doi. org/10.1186/1478-4491-10-43

19. Cogbill TH, Malangoni MA, Potts JR, Valentine RJ. The general surgery milestones project. J Am Coll Surg. 2014;218(5):1056-1062. https://doi. org/10.1016/j.jamcollsurg.2014.02.016

20. Chen HC, McNamara M, Teherani A, Cate OT, O'Sullivan P. Developing entrustable professional activities for entry into clerkship. Acad Med. 2016;91(2):247-255. https://journals.Iww.com/ academicmedicine/Fulltext/2016/02000/Developing Entrustable Professional Activities for.31. aspx 